\title{
Parkinsonismo como síntoma principal de hiperparatiroidismo: recuperación tras cirugía
}

\author{
Parkinsonism as presenting symptom of primary hyperparathyroidism: Improvement after \\ surgery \\ Delia Luján-Martínez*, Ángela Sánchez-Cifuentes, Emilio Peña-Ros, Antonio Albarracín-Marín-Blázquez y \\ Mari Fe Candel-Arenas \\ Servicio de Cirugía General y del Aparato Digestivo, Hospital General Universitario Reina Sofía, Murcia, España
}

\begin{abstract}
Resumen
Introducción: La hipercalcemia puede causar diferentes trastornos neurológicos, dependiendo de las concentraciones de calcio. Aportamos un caso excepcional de hiperparatiroidismo primario que se manifestó con deterioro neurológico rápidamente evolutivo y se resolvió mediante paratiroidectomía. Caso clínico: Mujer de 74 años que consultó por deterioro cognitivo progresivo y alteración de las funciones motoras. Las pruebas complementarias evidenciaron hipercalcemia debida a un adenoma paratiroideo. Se realizó paratiroidectomía, con mejoría sintomática. Conclusión: El deterioro cognitivo del anciano por un adenoma paratiroideo está infradiagnosticado, pues los cambios de conducta y las alteraciones de las funciones motoras se atribuyen a la edad, la demencia y la fragilidad, suponiendo un reto diagnóstico.
\end{abstract}

PALABRAS CLAVE: Parkinsonismo. Hiperparatiroidismo primario. Hipercalcemia.

\begin{abstract}
Introduction: Hypercalcemia can cause different neurological disorders, depending on the calcium level. We report an exceptional case of primary hyperparathyroidism presenting as neurological alteration and it has favourable outcome after parathyroidectomy. Case report: A 74-year-old woman presented with progressive cognitive deterioration and impaired motor function. The complementary tests showed hypercalcemia due to a parathyroid adenoma. Parathyroidectomy was performed with symptomatic improvement. Conclusion: Cognitive impairment of the elderly due to a parathyroid adenoma is underdiagnosed, behavioral changes and alterations of motor functions are attributed to age, dementia and frailty, representing a diagnostic challenge.
\end{abstract}

KEY WORDS: Parkinsonism. Primary hyperparathyroidism. Hypercalcemia. 


\section{Introducción}

Las manifestaciones clínicas del hiperparatiroidismo primario (HPTP) se relacionan con el exceso de paratohormona (PTH) circundante y con la hipercalcemia. Los valores elevados de calcio pueden causar diferentes trastornos neurológicos ${ }^{1}$. Aportamos un caso excepcional de HPTP que se manifestó con parkinsonismo rápidamente evolutivo y se resolvió tras la paratiroidectomía.

\section{Caso clínico}

Mujer de 74 años con antecedentes de hipertensión, dislipidemia, asma intrínseca e histerectomía, que consultó por deterioro cognitivo progresivo con alteración de las funciones motoras, desorientación parcial, bradipsiquia y alteración de la marcha de instauración rápida, todos ellos síntomas sugestivos de parkinsonismo.

La resonancia magnética cerebral (Fig. 1) destacó lesiones isquémicas crónicas de pequeño vaso, índice de parkinsonismo 10, no sugestivo de parálisis supranuclear progresiva. Se realizó una analítica que mostró calcio $14 \mathrm{mg} / \mathrm{dl}$, fósforo $2.1 \mathrm{mg} / \mathrm{dl}$, PTH $483 \mathrm{pg} / \mathrm{ml}$, marcadores tumorales normales y función renal sin alteraciones. La ecografía cervical (Fig. 2) informó de tiroides aumentado de tamaño con nódulos bilaterales de hasta $11 \mathrm{~mm}$, y adyacente al polo inferior del lóbulo tiroideo izquierdo se observó un nódulo bien delimitado, hipoecoico y homogéneo, con un tamaño de unos $10 \mathrm{~mm}$, de probable origen paratiroideo.

Se instauró tratamiento con ácido zoledrónico y tras la normalización de los parámetros analíticos la paciente presentó mejoría sintomática, caminando sin apoyo, con marcha ágil y sin temblor, con recuperación de su estado basal. Se intervino de forma programada y se hallaron un nódulo tiroideo derecho y un adenoma paratiroideo inferior derecho. Se realizaron hemitiroidectomía y paratiroidectomía, comprobando intraoperatoriamente el descenso de la PTH y realizando estudio histopatológico de tejido paratiroideo.

La anatomía patológica informó de adenoma de paratiroides de $3.27 \mathrm{~g}$ y hemitiroides con nódulo coloide. Actualmente asintomática, con calcemia y PTH normales.

\section{Discusión}

El HPTP es un trastorno endocrino que afecta principalmente a mujeres posmenopáusicas alterando el

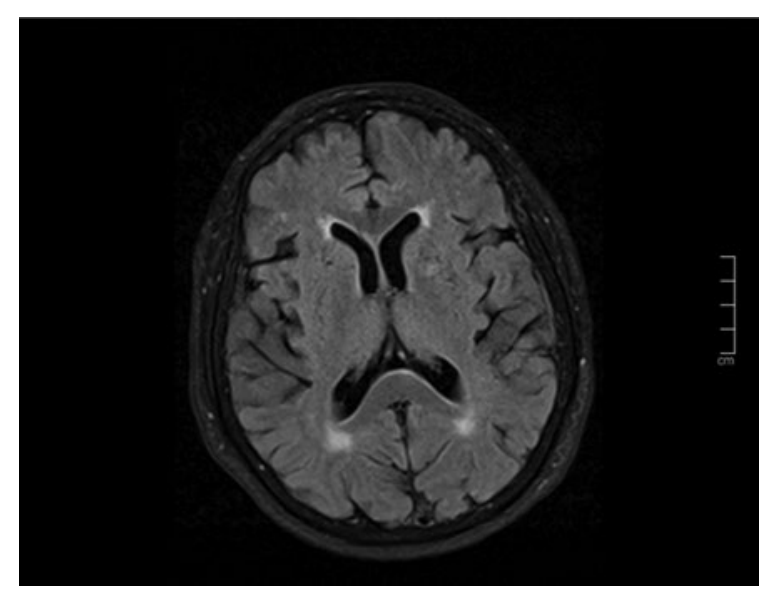

Figura 1. Resonancia magnética cerebral que muestra lesiones isquémicas de pequeño vaso.

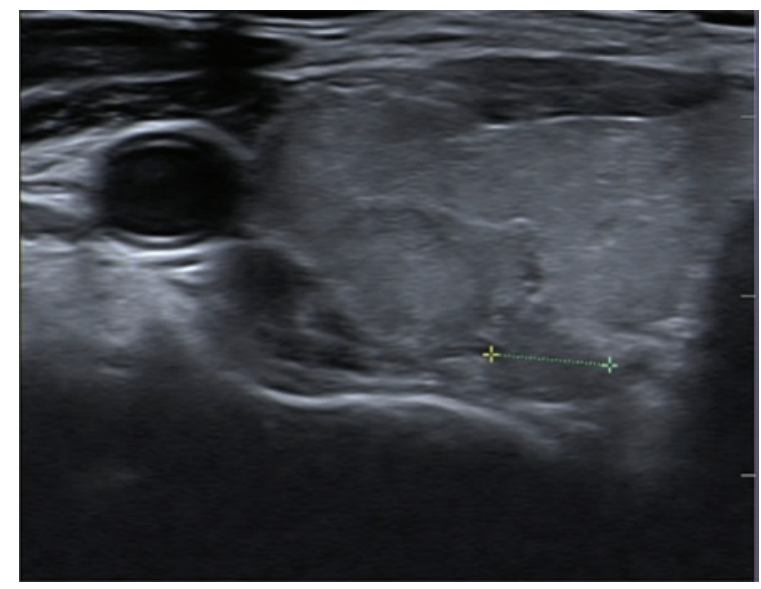

Figura 2. Ecografía cervical en la que se visualiza hemitiroides izquierdo con varios nódulos, y adyacente al polo inferior un nódulo bien delimitado, hipoecoico y homogéneo, de unos $10 \mathrm{~mm}$, de probable origen paratiroideo.

metabolismo fosfocálcico. Estos pacientes suelen presentar nefrolitiasis, osteítis fibrosa quística o litiasis renal recurrente, todos ellos ausentes en nuestra paciente ${ }^{2}$. El parkinsonismo como síntoma de presentación de HPTP es extremadamente raro, con muy pocos casos descritos en la literatura ${ }^{3-5}$.

La alteración de la homeostasis entre el calcio y la PTH puede ser un factor de riesgo o un agravante para el desarrollo de parkinsonismo. El calcio es necesario para la regulación de la excitabilidad de la membrana neuromuscular y la liberación de neurotransmisores. Concentraciones elevadas de calcio pueden influir en la estructura y la función del receptor de dopamina, interrumpiendo la señalización neuronal ${ }^{1,5}$.

El deterioro cognitivo global en el anciano debido a un adenoma paratiroideo está infradiagnosticado. Los cambios de conducta y las alteraciones de las funciones motoras suelen atribuirse a la edad, la demencia 
y la fragilidad, suponiendo un reto diagnóstico. Por tanto, estos pacientes pueden beneficiarse del tratamiento médico-quirúrgico, como en el caso de nuestra paciente, que presentó una notable recuperación de todas las funciones cognitivas y motoras tras la corrección de la hipercalcemia y la paratiroidectomía.

\section{Responsabilidades éticas}

Protección de personas y animales. Los autores declaran que para esta investigación no se han realizado experimentos en seres humanos ni en animales.

Confidencialidad de los datos. Los autores declaran que han seguido los protocolos de su centro de trabajo sobre la publicación de datos de pacientes.

Derecho a la privacidad y consentimiento informado. Los autores han obtenido el consentimiento informado de los pacientes y/o sujetos referidos en el artículo. Este documento obra en poder del autor de correspondencia.

\section{Financiamiento}

Los autores declaran la no existencia de financiación externa.

\section{Conflicto de intereses}

Los autores declaran la no existencia de conflictos de intereses.

\section{Bibliografía}

1. Lourida I, Thompson-Coon J, Dickens CM, Soni M, Kuźma E, Kos K, et al. Parathyroid hormone, cognitive function and dementia: a systematic review. PLoS One. 2015;10:e0127574.

2. Bandeira L, Bilezikian J. Primary hyperparathyroidism. F1000 Research. 2016;5:F1000 Faculty Rev-1.

3. Hirooka Y, Yuasa K, Hibi K, Ishikawa A, Sobue G, Naruse T, et al. Hyperparathyroidism associated with parkinsonism. Intern Med. 1992;31:904-7.

4. Kovacs CS, Howse DC, Yendt ER. Reversible parkinsonism induced by hypercalcemia and primary hyperparathyroidism. Arch Intern Med. 1993;153:1134-6.

5. De Rosa A, Rinaldi C, Tucci T, Pappata S, Rossi F, Morra VB, et al. Co-existence of primary hyperparathyroidism and Parkinson's disease in three patients: an incidental finding? Parkinsonism Relat Disord. 2011;17:771-3. 